\title{
The Anticipatory Governance of Emerging Technologies
}

\author{
David H. Guston* \\ Politics and Global Studies, Center for Nanotechnology in Society at ASU, \\ Consortium for Science, Policy \& Outcomes, Arizona, USA \\ (Received June 21, 2010, Revised August 30, 2010, Accepted October 18, 2010)
}

\begin{abstract}
The Center for Nanotechnology in Society at Arizona State University (CNS-ASU) is a Nano-scale Science and Engineering Center (NSEC) funded by the US National Science Foundation (NSF). It implements an agenda of "real-time technology assessment" (RTTA) in pursuit of a strategic vision of the "anticipatory governance" of nanotechnologies. To achieve this vision, CNS-ASU unifies research programs not only across several universities but also across three critical, component activities: foresight (of plausible future scenarios), integration (of social science and humanities research with nano-scale science and engineering), and engagement (of publics in deliberations). CNS-ASU also performs educational and training activities as well as public outreach and informal science education. This paper elaborates the Center's strategic vision of anticipatory governance and its component activities, especially in the context of extending the concerns of societal dimensions research beyond the traditional risk paradigm.
\end{abstract}

Keywords : Nanotechnology, Anticipatory governance, Societal dimensions, Center for nanotechnology in society

\section{Introduction}

In 2003, the United States Congress passed and President George W. Bush signed the $21^{\text {st }}$ Century Nanotechnology R\&D Act. The Act authorized the National Nanotechnology Initiative (NNI), which had begun under Bush's predecessor, President Bill Clinton, in 2000 [1]. While the roots of the approach that the US takes to address the societal dimensions of nanotechnologies extend to the creation of NNI [2], this approach is most clearly articulated in the Act, which has four concrete provisions related to societal dimensions [3]: 1) It establishes a societal dimensions research program. 2) It requires the large Nano-scale
Science and Engineering Centers (NSECs) created by the National Science Foundation (NSF) to address societal implications of nanotechnologies. 3) It requires the integration of societal concerns into nano-scale research for the benefit of the American public. 4) And it requires regular public input into decision making for nano-scale research.

The Act provided the background for both NSF's request for proposals for a "Center for Nanotechnology in Society" - which was issued in 2004 - as well as for the response to that request from Arizona State University. Indeed, ASU's proposal specifically invoked the legislation and designed its approach to address the congressional interest in public engage-

*[E-mail] david.guston@asu.edu 
ment with nano-scale science and engineering (NSE) research and the integration of societal concerns with NSE research as well. Although NSF initially conceived of funding one Center for Nanotechnology in Society at about $\$ 13$ million, it ultimately decided to "split the pot" and award two centers - one at ASU (CNS-ASU) and one at University of California, Santa Barbara (CNS-UCSB) - and fund them at $\$ 6.2$ million and $\$ 5$ million, respectively, over the period 2005-2010. Each center represented activities of researchers not only at the host university but at other universities across the US and elsewhere in the world.

CNS-ASU proposed two sets of research programs, organized in an overlapping or matrix fashion. The first set of "real-time technology assessment" (RTTA; [4]) programs is more methodologically driven. RTTA 1, Research and Innovation Systems Analysis program, is grounded in data-mining from large-scale bibliographic and patent data bases. RTTA 2, Public Opinion and Values, is grounded in surveys of both the general public and scientists. RTTA 3, Anticipation and Deliberation, draws from methods to explore futures of nanotechnologies through scenario development and to deliberate on them through novel public engagement activities. RTTA 4, Reflexivity and Integration, uses both interviews and ethnographic methods to explore and assess the possibilities of changes in perspectives and practices among the NSE researchers with whom CNS-ASU collaborates.

The second set programs, the "thematic research clusters" (TRCs), are more curiosity-inspired but draw on the methodological expertise in the RTTAs and provide substantive content them. The initial proposal offered four TRCs - Freedom, Privacy and Security; Human Identity, Enhancement and Biology; Environmental Health and Safety; and Equity and Political Economy - but the reduction in the budget from the proposed $\$ 13$ million to the awarded $\$ 6.2$ million caused CNS-ASU to eliminate the latter two programs. Over the course of the first five years, CNS-ASU also moved away from Freedom, Privacy and Security and instead substituted a recrafted TRC on Equity, Equality and Responsibility. For its renewal period (2010-2011), CNS-ASU will retire Human Identity, Enhancement, and Biology and begin a new theme of Urban Design, Materials, and the Built Environment, also known as "Nano and the City."

The overall goal of the collection of and interaction among these programs is contributing to the development of two, broad-based societal capacities: reflexivity and anticipatory governance. By reflexivity, we mean a capacity for social learning among individuals, groups, institutions and publics in the NSE enterprise narrowly but in society more broadly that expands the domain of and informs the available choices in decision making about nanotechnologies. By anticipatory governance, we mean a capacity extended throughout society that can act on a variety of inputs to manage emerging knowledge-based technologies (of which nano is but one) while such management is still possible. As CNS-ASU has developed, anticipatory governance has become its core strategic vision, and the rest of this paper will develop the center's intellectual and operational approach to it.

\section{Anticipatory Governance}

In order to fully understand the meaning of anticipatory governance at CNS-ASU, one must first understand that the concept of "anticipation" as we use it is distinct from concepts of prediction or expectation. Rather, our concept of anticipation strongly reflects its etymology from the Latin as "ante-" meaning "beforehand" and "capere" meaning to take into possession. It is related to "capability" and "capacity" and denotes the ability to take something in beforehand. It is not a synonym for 
"predict", "expect," or "foresee".

While the efforts of CNS-ASU to pursue anticipatory governance are quite recent, the inspiration behind the vision has an extensive history. One can trace, for example, the hopes for productive collaborations between social scientists and natural scientists to Detlev Bronk - then president of The Johns Hopkins University and later president of the National Academy of Sciences and the Rockefeller University - who in 1945 testified to Congress in support of using the proposed NSF to fund social science by arguing: "Competent social scientists should work hand-in-hand with natural scientists, so that problems may be solved as they arise, and so that many of them may not arise in the first instance" [5].

On the governance side, anticipatory governance is meant to partake in a discussion in which governance is a wider set of activities than mere "government" that is, actions by public sector authorities [6]. This wider set of activities is also meant to create between the two simple but extreme options that often dominate discussions of the governance of emerging technologies: "doing" and "banning." In the case of nanotechnologies, the "doing" is represented by a technological determinist position where, in real instances, advocates quote from the slogan of the 1933 Chicago World's Fair that "Science finds, genius invents, industry applies, man adapts." The "banning" is represented by numerous calls for moratoria on NSE research and development, at least until conditions of environmental health and safety are met. Options between these two extremes include the implementation of licenses and other kinds of restrictions, the use of liability and indemnification, the application of intellectual property rights, the execution of treaties, the development of standards, testing regimes, and codes of conduct, and public action in various forms ranging from education to protest. It also views the laboratory as an important locus of governance.
As a term of art, "anticipatory governance" itself does not seem to appear in the literature in any significant way prior to 2001 [7], but it may very well be related to an earlier usage of the term "anticipatory democracy" by Alvin Toffler in his influential Future Shock (1971) to denote a desired style of distributed and participatory attention to the governance of technological change as an antidote to the "future shock" that Toffler believed was causing widespread alienation in modern society. The meaning of anticipatory governance at CNS-ASU is not radically different from Toffler's, although we distinguish four separate capacities that involve both research and practice: foresight, engagement, integration, and "ensemble-ization" [8, 9].

\section{Foresight}

As described above, the approach to the future of anticipatory governance involves a rejection of prediction but an embrace of an approach to foresight we call anticipation, which casts multiple, plausible futures as objects for deliberation rather than a single predicted future as an object of pursuit [10]. CNS-ASU has designed several research activities to anticipate nanotechnologies, including the development of and deliberation on scenes of NanoFutures, more formal scenario development workshops with multiple stakeholders, the design of future products through InnovationSpace, and the exploration of new concepts in the Plausibility Project.

\section{NanoFutures}

The NanoFutures project (http://cns.asu.edu/nano futures/) aims to create, review and disseminate plausible visions of nanotechnological futures to serve as bases for deliberation. Because most of the nanotechnologies that are now in commerce, e.g., 
those catalogued by the Woodrow Wilson International Center's Project on Emerging Nanotechnologies, show little hints of the revolutionary potential that forms the rationale for most investments in nano, concrete, plausible visions of such potential can help stimulate early discussion and hone ethical sensibilities and deliberative habits. CNS-ASU has produced a set of NanoFuture scenes on human enhancement technologies [11] and is producing a set on nano energy technologies. In each case, the scenes are written creatively from the scientific and professional literature, reviewed by relevant NSE researchers to eliminate technical failings, and formatted and distributed for discussion in classrooms and beyond.

\section{Scenario Development Workshops}

CNS-ASU has conducted three formal visioning or scenario development workshops. In one, we partnered with a laboratory engaged in use-inspired research to create a table-top nano-fluidics device to scan small amounts of blood, urine or saliva for biomarkers for the pre-symptomatic diagnosis of disease [12]. In a second, we partnered with an energy research group preparing to enter a major competition to develop new technologies to turn sunlight into liquid fuels without going through organisms [13]. In a third, we turned our scenario development methods reflexively on ourselves and envisioned futures in which anticipatory governance had a variety of roles [14]. In each case, the workshops provided important strategic guidance to the researchers they serviced and, in the particular case of the pre-symptomatic diagnostic technology, the workshop led to changes in research focus among the NSE researchers.

\section{InnovationSpace}

Recognizing that the skills dealing with nanotechnological futures in the long run are not limited to the texts and narratives involved in NanoFutures, CNS-ASU developed a partnership with a research and education unit at ASU called InnovationSpace (see innovationspace.asu.edu). A partnership among design, engineering, and business, InnovationSpace trains senior undergraduates from each of those disciplines to collaborate in cross-functional teams to design and develop a new product in creative but sustainable ways. Alongside private sector partners like Intel and Herman Miller, CNS-ASU sponsors three teams of students in a year-long project to design new nanotechnologies, ranging from applications in health to energy.

\section{Plausibility Project}

Faced with the challenge of creating provocative yet grounded scenes for the NanoFutures project, CNS-ASU researchers realized that the concept of plausibility - which is often used to assess anticipatory knowledge in future scenarios - is under-developed. The Center thus decided to embark on a project to explore plausibility, organizing an international workshop in November 2009, publishing a report [15] and establishing an ongoing collaboration with the Institute for Science, Innovation and Society at Oxford University. An early insight of this work is that plausibility may prove to be a fruitful complement or even alternative to probability in assessing plural visions of the future (see also www.cspo.org/projects/plausibility/).

\section{Engagement}

Engagement involves a connection between nanoscale science and engineering researchers with general publics that, at its best, provides for a two-way exchange of information and that tends to create a mutual understanding of values and goals. CNS-ASU 
has designed several engagement activities, ranging from the large-scale and intensive National Citizens' Technology Forum to its small-scale Science Cafes. The center is also involved in a deepening collaboration with the Nano-scale Informal Science Education Network to reach larger numbers of the general public with information about nanotechnologies that is more sensitive to its societal dimensions.

\section{National Citizens' Technology Forum}

In Spring 2008, CNS-ASU organized the most ambitious public engagement activity around nanotechnology in the US, the National Citizens' Technology Forum (NCTF). Modeled after the Danish consensus conference but distributed across six locales across the United States, the NCTF on "nanotechnologies and human enhancement" demonstrated that a high-quality deliberative activity can be organized at a national scale in the US, and that a representative selection of lay-citizens can come to discerning judgments about nanotechnologies while they are still emergent [16]. While there are reasonable concerns about the quality of the particular online component of the process [17] and the demandsthat such intensive activities place on citizens [18], the NCTF process is a sound demonstration upon which to build future citizen deliberations [19].

\section{NISE Net}

In addition to funding the CNS-ASU and other nano-scale science and engineering centers, NSF funds a Nano-scale Informal Science Education Network (NISE Net) to conduct education and outreach through informal settings, i.e., not classrooms but science museums and other non-scholastic environments. For example, NISE Net distributes a set of easy-to-use table-top demonstration materials that communicate the basics of NSE to more than
300 science museums across the United States as part of its "NanoDays" activities. CNS-ASU has provided NISE Net with a number of additions and innovations to the NanoDays kit, including a background paper for museum personnel on the top societal issues in nanotechnology [20] posters that ask and answer some of the most frequent questions that museum personnel get from the public. This burgeoning partnership includes plans for collaborative work on more permanent demonstrations, exhibits and programs, some of which NISE Net stylizes after anticipatory governance [21].

\section{Science Cafes}

The Science Café movement (see www.sciencecafes. org) has been active in the US and Europe over the last several years, creating informal ways for natural scientists and engineers and lay citizens to meet and interact around current research topics and issues. CNS-ASU produces a successful Science Café series, hosted one Friday each month during the academic year by the Arizona Science Center in downtown Phoenix. The CNS-ASU science café created a minor innovation in format by pairing a social scientist or humanist with a natural scientist or engineer, thus continuing to break down the barrier of expertise that separates the academic scientist or engineer from the lay citizens by creating an initial discussion among experts that can then spread to the audience. The series maintains attendance on average of 40-50 people. In addition to outreach and informal education opportunities, the Science Cafes operated by CNSASU provide continuing education credits to in-service teachers.

\section{Integration}

Integration involves creating activities that require 
close collaboration between scientists and engineers on the one hand and social scientists on the other. Many integrative activities include training in dividuals from side in the perspectives, methods, etc., of the other. Specifically identified in the 2003 Act without being defined, integration can include both research and educational activities as described here.

\section{Socio-Technical Integration Research}

CNS-ASU has created a set of laboratory studies and engagements that are not traditional laboratory ethnographies with their focus on observation and explication, but rather efforts to integrate social science and humanities with NSE research. The major such activity - the "Socio-Technical Integration in Research" (STIR) project (see http://www.cspo.org/ projects/stir/) - coordinates a set of twenty comparative, international, intervention-oriented ethnographies in North America, Western Europe, and East Asia. The project trains a group of ten doctoral students in a framework developed [22] both to conduct socio-technical collaborations and to assess the policy relevance of their outcomes. Typical project findings include strong indications of both the possibility and the utility of socio-technical collaborations, including increases in reflexive awareness among the observed scientists and engineers, changes in their laboratory practice, and ongoing effects and contact between the host scientists and the STIR researcher.

\section{Education}

CNS-ASU has also created a set of integrative educational experiences for students across the disciplines, although most focus on integrating societal dimensions training of graduate students in science and engineering. In particular, CNS-ASU has an associated grant from NSF through its Ethics Education in Science and Engineering (EESE) program to develop and evaluate four different models for graduate ethics education. Three of these models that were originally developed by CNS are already being offered on a regular basis. A stand-alone course model has been offered every semester since F 08 and has spawned two additional versions focused on specific topics like energy and developing countries. An embedded course model has been offered annually in conjunction with a new $\mathrm{PhD}$ program in biological design. Building on earlier work done at $\mathrm{CNS}$, one project team met five times over a semester with the lab group during its normal meetings and discussing the ethical concerns that emerged from the lab group, which dwelt most significantly about the ethical treatment of their animal research subjects - most of whom are primates [23]. Preliminary evaluations of each of these interactions suggest the interventions were able to shift the discussion and outlook of the lab members. In addition to this grant-funded program, CNS-ASU also conducts a two-week summer session in Washington, DC to introduce science and engineering graduate students to "science outside the lab" (http://www.cspo.org/outreach/scienceoutsidethelab/) and coordinates a "PhD+" program that trains doctoral students in science and engineering in the societal dimensions of their own research and guides them in adding a chapter on societal dimensions to their dissertations [24, 25].

\section{Ensemble-ization}

Barben et al. [9] contend that these three activities or capacities of anticipatory governance cannot be built or performed separately but need instead to be performed ensemble - a term borrowed from Hackett et al. [24] to describe the creation of an assemblage of personnel, tools, instruments and techniques for large-scale research enterprises. The experience of 
CNS-ASU bears out this contention. For example, scenario development workshops require much of the same kind of close collaboration between natural and social scientists that occurs in integration activities. Public engagement on emerging technologies requires multiple visions of the future - as delivered by foresight activities - as grist for anticipatory analysis and evaluation. Integration activities require public values, as elucidated by engagement, to be brought into the laboratories to help inform the situation of responsible innovation there. Such an ensemble, encompassing foresight, engagement and integration, thus requires the kind of long-term and large-scale funding that NSF offers through the mechanism of the nano-scale science and engineering center.

Two concrete projects have demonstrated the power of the kind of ensembles that CNS-ASU has orchestrated around anticipatory governance. In one, related to the center's thematic research cluster on human identity, enhancement, and biology, researchers have demonstrated the kind of real-time assessments that can be done of nanotechnology and its relationship to neuro-science and technology [27]. While some otherwise informed observers have minimized the relevance and salience of nanotechnology in such areas and, thus, contribute to a closing down of dialogue [28], CNS-ASU research has revealed specific areas of intense scientific interest, developed plausible scenarios of socio-technical futures, elicited nuanced public values associated with specific technological applications and futures, and developed enduring partnerships with scientists and engineers. In a second ensemble, two researchers from CNS-ASU partnered with the city of Phoenix planning department through a graduate studio course on "Anticipatory Governance for Sustainability" to develop scenarios of urban development, elicit public engagement at the neighborhood level, and incorporate perspectives from emerging nanotechnologies into deliberations about the state-mandated, long-term plan for Phoenix. This effort not only provided rich and engaged pedagogy for the students, but it also provided much-needed assistance to the city of Phoenix and created a set of relationships and capacities upon which further action-oriented research will be based.

\section{Discussion and Conclusion}

This paper has described the strategic vision behind the research programs of the Center for Nanotechnology in Society at Arizona State University. To achieve its vision of the "anticipatory governance" of nanotechnologies, CNS-ASU creates research ensembles across three critical, component activities: foresight (of plausible future scenarios), integration (of social science and humanities research with nanoscale science and engineering), and engagement (of publics in deliberations). CNS-ASU also performs educational and training activities as well as public outreach and informal science education.

While this vision is still novel, it has had influence not only through scholarly publications of the kind cited here and planned for the future, but also through direct interactions with public sector officials - beyond the Phoenix planning department described above - at the Government Accountability Office, the Congressional Research Service, the Environmental Protection Agency, the National Nanotechnology Coordinating Office, and the Office of Science and Technology Policy in the United States, as well as officials in Flanders (Belgium), New Zealand, Australia, and Japan. CNS-ASU has also hosted more than 50 international visitors from 15 nations, most of whom were interested in delving into anticipatory governance in their work.

Implementing an agenda of anticipatory governance, however, faces at least four serious challenges: First, its individual techniques and methods need to be further refined through both research and 
practice. Foresight, engagement and integration, as performed at CNS-ASU, were all pushing the envelope. The center's role was to research and demonstrate the capacity necessary to perform them, but not to operationalize them fully or implement them. In the process, we discovered some both basic research problems lurking, e.g., that the concept of plausibility was under-developed in the practice and scholarship of scenario development, and issues of implementation, e.g., we demonstrated a national citizens' technology forum, but who will implement it with the goal of directly influencing policy? Second, these techniques and methods must remain ensemble, thus requiring large-scale investment in infrastructure, training, and projects by research sponsors or patrons. This necessary scale of activities is threatened in the United States, where the NSEC program that has funded the two centers for nanotechnology in society is scheduled to terminate, and it has never really been achieved in other countries despite somewhat generous funding for societal research in northern and western Europe. Third, even with sufficiently refined and supported methods of research and practice, anticipatory governance also requires a change of disposition among an array of important actors in order to thrive. Foresight must be understood to be a less predictive and more openended endeavour. Public engagement must pursued in a less instrumental and more communicative spirit. And integration must mean partnership across the disciplines rather than service of one to the others. These dispositional changes need to occur not only among scientists and science policy makers, but across a broad segment of policy makers and the general public.

While certainly daunting, meeting these challenges over the long-term is not impossible. One model of change in both practice and ideology of the research system is the commercialization of university research since roughly 1980, when the US Congress passed the Bayh-Dole Act. Although economic activity by university scientists was not unprecedented, Bayh-Dole authorized such activity in local academic cultures less well disposed toward it and, with the promise of unrestricted income from exclusive licenses on academic patents, provided incentives for institutional change as well. Elements of anticipatory governance are as deeply seated in the research enterprise as commercialization was, but the fourth and final challenge for anticipatory governance would be identifying the appropriate incentives for institutional change and the political coalitions necessary to implement them.

\section{References}

[1] W. P. McCray, Hist and Tech. 21, 177 (2005).

[2] M. C. Roco and W. S. Bainbridge (eds.), Societal Implications of Nanoscience and Nanotechnology (US National Science Foundation, Arlington, 2001).

[3] E. Fisher and R. L. Mahajan, Sci. Pub. Pol. 33, 5 (2006).

[4] D. H. Guston and D. Sarewitz, Tech. in Soc. 24, 93 (2002).

[5] D. W. Bronk, Science 188, 409 (1975).

[6] C. Lyall and J. Tait (eds.), New Modes of Governance (Ashgate, Aldershot, 2005).

[7] R. Karinen and D. H. Guston in M. Kaiser, M. Kurath, S. Maasen, and C. Rehmann-Sutter (eds.), Governing Future Technologies (Springer, Dordrecht, 2010), pp.217-232.

[8] D. H. Guston, Nature 454, 940 (2008).

[9] D. Barben, E. Fisher, C. Selin, and D. H. Guston in E. J. Hackett, O. Amsterdamska, M. Lynch, and J. Wajcman (eds.), The Handbook of Science and Technology Studies, Third Edition (MIT Press, Cambridge, 2008), pp.979-1000.

[10] C. Selin, Sci, Tech. \& Hum. 32, 196 (2007).

[11] I. Bennett in E. Fisher, C. Selin, and J. Wetmore 
(eds.), Yearbook of Nanotechnology in Society, Volume 1 (Springer, New York, 2008), pp.149-156.

[12] C. Selin, The Future of Medical Diagnostics, \#R080001 (Center for Nanotechnology in Society, Arizona State University, Tempe, 2008).

[13] S. Davies and C. Selin, Solar to Fuels, \#R10-0002 (Center for Nanotechnology in Society, Arizona State University, Tempe, 2008).

[14] C. Selin, CNS Visioning Workshop, \#R08-0002 (Center for Nanotechnology in Society, Arizona State University, Tempe, 2008).

[15] C. Selin, et al., Plausibility Project Workshop \#R100001 (Center for Nanotechnology in Society, Arizona State University, Tempe, 2010).

[16] P. Hamlett, M. Cobb, and D. H. Guston, National Citizens Technology Forum: Nanotechnologies and Human Enhancement, \#R08-0003 (Center for Nanotechnology in Society, Arizona State University, Tempe, 2008).

[17] J. A. Delborne, A. A. Anderson, D. L. Kleinman, M. Colin, and M. Powell. Public Understanding of Science. Published online first as doi: 10.1177/ 0963662509347138 (2009).

[18] D. L. Kleinman, J. A. Delborne, and A. A. Anderson. Public Understanding of Science. Published online first at doi: 10.1177/0963662509347137 (2009).

[19] M. Philbrick and J. Barandiaran, Sci. Pub. Pol. 36,
335 (2009).

[20] C. A. Miller, D H. Guston, D. Barben, J. Wetmore, C. Selin, and E. Fisher. Nanotechnology and Society: Ideas for Education and Public Engagement, \#R070001 (Center for Nanotechnology in Society, Arizona State University, Tempe, 2007).

[21] L. Bell, Museums and Soc. Iss. 4, 21 (2009).

[22] E. Fisher, R. L. Mahajan, and C. Mitcham, Bull Sci. Tech. Soc. 26, 486 (2006).

[23] J. McGregor and J. Wetmore, Nanoethics 3, 17 (2009).

[24] T. Benn, The Release of Engineered Nanomaterials from Commercial Product (Doctoral Dissertation, Civil and Environmental Engineering, Arizona State University. Tempe, 2009).

[25] J. Lappe, Photoreactivation and Positive Cell Selection for the Directed Evolution of Proteins (Doctoral Dissertation, Chemistry and Biochemistry, Arizona State University, Tempe, 2009).

[26] E. Hackett, D. Conz, J. Parker, J. Bashford, and S. DeLay. Res. Pol. 33, 747 (2004).

[27] J. Robert, C. Miller, I. Bennett and S. Hays (eds.), Yearbook of Nanotechnology in Society, Volume 3 (Springer, New York, forthcoming 2011).

[28] L. Zonneveld, H. Dijstelbloem, and D. Ringoir, Reshaping the Human Condition: Exploring Human Enhancement (Rathenau Institute, The Hague, 2008). 


\title{
떠오르는 기술들에 대한 예비 협치
}

\author{
David H. Guston* \\ Politics and Global Studies, Center for Nanotechnology in Society at ASU, \\ Consortium for Science, Policy \& Outcomes, Arizona, USA \\ (2010년 6월 21일 받음, 2010년 8월 30일 수정, 2010년 10월 18일 확정)
}

\begin{abstract}
아리조나 주립대학교의 사회 속의 나노기술 센터(CNS-ASU)는 미국 자연과학기금(NSF)에서 지원하는 나노 스케일 과학 및 공학 센터(NSEC)이다. 이 센터는 나노기술의 '예비 협치'(anticipatory governance)의 전략적 비전을 위한 실시간 기술 평가 를 구현한다. 이 비전을 달성하기 위하여, $\mathrm{CNS}-\mathrm{ASU}$ 는 몇 개 대학의 연구사업을 통합할 뿐 아니라 예견(그럴듯한 미래 시나 리오), 집적(사회인문과학을 나노스케일 과학기술과 연계) 및 참여(대중에게 홍보) 등 세 개의 주요 활동을 통합한다. $\mathrm{CNS}-\mathrm{ASU}$ 는 교육 훈련 활동을 할 뿐만 아니라 대중 소통과 비공식적 과학 교육을 실시한다. 이 논문은 이 사업은 전통적인 위험 관리 체계를 뛰어 넘는 사회적 차원의 연구를 포함한 예비 협치의 내용과 전략적 전망을 논술하고 있다.
\end{abstract}

주제어 : 나노기술, 예비 협치, 사회적 차원, 사회속의 나노기술 센터

* [전자우편] david.guston@asu.edu 